\title{
Aeine Worreds.
}

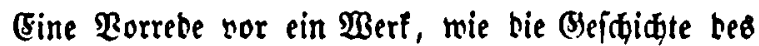
Bhilofophen Ianifdumenb? - Nein, bei IUtem, mas gut ift, id merbe feine Burrebe baju madien, es erjolge aud baraud, was will!

Für ben serfintigen Sejer wirbe bie firzep̃e zu lang fonn: unb bem unneritanbigen bilft feire Borrebe, unb wenn fie breimal linger wire, als bas $\mathfrak{B}_{\text {Berf fellft. }}$

(58 gibt Reute, fagte mir einer meiner Sreunbe (in Der weitern Beteutung bes $\mathfrak{B o r t e b ) , ~ b i e ~ l i n t e r ~} 3$ then Eultanen unb Bonjen ganj mos 2libres fudten -

"2lls Eultane unb Bonzen? - Da haben bie Reute Unredt, Freund:"

2ber esibt num einmal folde Sefer, gegen bie man

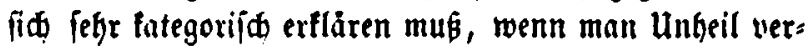

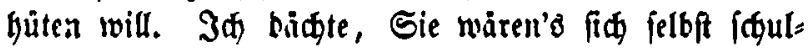
big, biefen geuten ein für alle $\mathfrak{T a l}$ fo beutlid, als nur immer moglid ifi, ju fagen, wie Sie verftanben fenn mollen. 


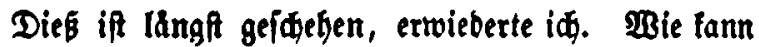

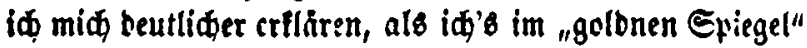

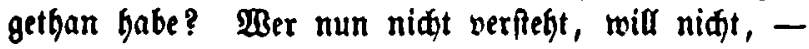
ober befinbet fid im Jalle bes ehrlidien Mannes, ber alle Brillen eines ganjen Rabens probirte, ohne einen Buduftaken baburd lefen zul tönnen; am Enbe zeigte fid's, baß ber Mann weber mit nod shne Brille lejen founte.

Sdyaffe mir sinber, ober id fterbe, fagte Rabel zu Safob, iljrem Manne. Bin id beun Bott? antwoortste ber Erzonter. - Dieß if gerabe ber Fall eines egrliden Alutors, bell unberitänbige Refer jwingen wollen, ifgnen Berftanb ju geben.

Siфht ift llur siat für be:l Sehenten: ber Blinbe wambelt im Connenidein unb büft fid im Finftern. 2llfo teine Borrebe! - 